\title{
Physicians' preventive practices: more frequently performed for male patients and by female physicians
}

Raphaëlle Delpech" ${ }^{1 *}$, Géraldine Bloy², Henri Panjo ${ }^{3,4}$, Hector Falcoff ${ }^{5}$, Virginie Ringa ${ }^{3,4}$ and Laurent Rigal ${ }^{1,3,4}$

\begin{abstract}
Background: We sought to analyze gender differences in General Practitioners' (GP) preventive practices: variations according to the GP's and the patient's genders, separately and combined, and the homogeneity of GPs' practices according to gender.

Methods: Fifty-two general practitioners volunteered to participate in a cross-sectional study. A sample of 70 patients (stratified by gender) aged 40-70 years was randomly chosen from each GP's patient panel. Information extracted from the medical files was used to describe the GPs' preventive practices for each patient: measurements of weight, waist circumference, glucose, and cholesterol; inquiry and counseling about smoking, alcohol consumption, diet, and physical activity, and dates of cervical smears and mammographies. An aggregate preventive score was calculated to assess the percentage of these practices performed by each GP for patients overall and by gender. Mixed models were used to test for gender differences.
\end{abstract}

Results: Questionnaires were collected in 2008-2009 for 71\% of the 3640 patients and analyzed in June 2017. Male patients and female GPs were associated with the most frequent performance of many types of preventive care. The aggregate preventive score was higher for male patients $(\mathrm{OR}=1.60,95 \% \mathrm{Cl} 1.47-1.75)$ and female GPs $(\mathrm{OR}=1.35,95 \% \mathrm{Cl} 1.05-1.73)$. There was no combined effect of the genders of the two protagonists. Female patients of male GPs appeared to receive preventive care least frequently and female GPs to deliver preventive care more consistently than their male colleagues.

Conclusion: Physicians need to be aware of these differences, for both patient gender and their own.

Keywords: Primary health care, Family practice, General practice, Gender, Preventive medicine, Preventive care, Patient-physician gender concordance, women's health

\section{Background}

Numerous studies have examined the influence of the gender of both the patient and the physician on the quality of preventive care dispensed. Some preventive procedures appear to be performed more frequently among men and others among women. Men thus appear to receive

\footnotetext{
* Correspondence: raphaelle.delpech@gmail.com

1 General Practice Department, Université Paris-Saclay, Le Kremlin Bicêtre, France

Full list of author information is available at the end of the article
}

preventive cardiovascular care [1-3] and advice about tobacco and alcohol use [4] more frequently than women but diet and lifestyle advice less often [5, 6]. The physician's gender also appears to be associated with the provision of preventive care. On the whole, women doctors appear to provide this care more often than their male colleagues, as demonstrated for cardiovascular prevention $[1,2]$, cancer screening $[4,7,8]$, and vaccination $[9,10]$. This result has nonetheless not been found systematically, and some aspects of prevention, such as prevention of overweight/

C C The Author(s). 2020 Open Access This article is licensed under a Creative Commons Attribution 4.0 International License, which permits use, sharing, adaptation, distribution and reproduction in any medium or format, as long as you give appropriate credit to the original author(s) and the source, provide a link to the Creative Commons licence, and indicate if changes were made. The images or other third party material in this article are included in the article's Creative Commons licence, unless indicated otherwise in a credit line to the material. If material is not included in the article's Creative Commons licence and your intended use is not permitted by statutory regulation or exceeds the permitted use, you will need to obtain permission directly from the copyright holder. To view a copy of this licence, visit http://creativecommons.org/licenses/by/4.0/ The Creative Commons Public Domain Dedication waiver (http://creativecommons.org/publicdomain/zero/1.0/) applies to the data made available in this article, unless otherwise stated in a credit line to the data. 
obesity and advice about cessation or reduction of smoking and drinking [4], do not seem to differ according to the physician's gender.

Beyond these somewhat contradictory observations, other aspects merit closer study. One of these is the combined effect of the gender of the patient and the doctor, currently the object of two hypotheses. First, effects of projection or identification might cause preventive care to be more frequent when the genders of each protagonist are concordant, as reported by a study of dietary-lifestyle advice and successful attainment of glycemic and blood-pressure goals [11]. Other studies, including some on this same dietary-lifestyle counseling topic [12, 13], have reported different results. Second, in the area of cardiovascular prevention, for example, practice differs less between patients of each gender when their primary care physicians are women compared with men [2]. To our knowledge, such analyses have not yet been conducted in other areas of prevention.

Finally, we assume that women physicians may have more consistent preventive practices among themselves than their male counterparts [14-16]. To our knowledge, the variation in physicians' preventive practices according to their gender has never been studied.

The overall objective of this study was to analyze the gender differences in the preventive of French general practitioners (GPs). More specifically, we sought to analyze the association between their preventive practices, on the one hand, and, on the other, the patient's gender, the GP's gender, and the combined effect of both, as well as to study the homogeneity of GPs' preventive practices according to their gender.

\section{Methods}

\section{Design}

This study is an ancillary analysis of data from an observational survey named PrevQuanti, designed to assess social inequalities in the preventive care - screening for breast and cervical cancer [17], tobacco, and alcohol consumption [18], and cardiovascular risk - provided by GPs to patients aged 40-74 years [2]. A power calculation determined that we would require $50 \mathrm{GPs}$ and 70 patients per GP to be able to demonstrate social gradients for the types of preventive care studied [19]. PrevQuanti was conducted in 2008-09 among GPs who supervised students training in general practice during an internship at their office. We used email and telephone to recruit GPs working with two medical school departments of general practice in the Paris metropolitan area (who were paid $300 €$ for their time). For each participating GP, a random sample of 35 men and 35 women was drawn from their patient list (patients who had reported them to be their regular GP), furnished by the national health insurance fund. In practice, we used the "random" function of Excel for the random drawing of patients from the list for each GP. There were no exclusion criteria.

\section{GPs' characteristics}

We collected the following GP characteristics, through a self-administered questionnaire: age, sex, mean duration of consultations, mean number of consultations weekly, and office location.

\section{Patients' characteristics}

A data collection template was used to extract characteristics of these patients' medical management from their files: number of visits during the past year, length of follow-up (management), and the preventive practices performed. A questionnaire mailed to patients' homes (for self-administration) collected various social characteristics, such as educational level [20].

\section{Statistical analysis}

In a preceding article we studied the assessment of cardiovascular risk for primary prevention according to the gender of patients and their GPs [2]. Here we continue our study of preventive care dispensed in general practice from a perspective focused on gender, but extend it on the one hand to other domains of prevention (overweight, alcohol consumption, diet, and gynecologic cancer screening) and on the other hand to the entire set of patients (without excluding those at high cardiovascular risk, as during our previous work). Binary dependent variables (that is, variables to be explained), obtained from the medical files, were used to describe the GPs' preventive practices. These variables were selected from RAND's Quality Assessment Tools, a set of quality indicators of preventive and chronic disease care developed and evaluated in the United States [21]. They are measures of process (more than result) and represent concrete activities that clinicians control rather directly [22]. Five domains of prevention (with 2 dependent variables per domain) were considered: weight management with weight and waist circumference measurements (ever documented in the file, regardless of when); substance use, with smoking and alcohol consumption status documented (ever documented in the file; smoking status was considered in our previous article); lifestyle recommendations, with provision of diet and physical activity advice (documented in the file within the past 3 years); cardiovascular risk with fasting blood glucose and cholesterol measurements (documented in the file within the past 5 years; both variables considered in the previous article); and gynecological cancer screening with cervical smear and mammography dates documented (ever documented in the file).We also constructed an aggregate preventive score. Calculated at the patient level, it was 
the percentage of the preventive practices performed among all the dependent variables applicable to both genders.

All of the analyses were performed with mixed logistic models with a random intercept, adjusted for characteristics of patients and GPs known to be associated with the dependent variables studied. The patient characteristics used for adjustment were: age (in 5-year groups), body mass index $\left(\mathrm{BMI}<25 \mathrm{~kg} / \mathrm{m}^{2}-[25-30]->30\right)[23,24]$, educational level (did not pass the "bac" school-leaving exam, passed the "bac", university level) [25], the annual number of visits $(0,[1,2], \geq 3)[26,27]$, the length of the patient-GP relationship ( $[0-1[,[1,2], \geq 3$ years). The GP characteristics used for adjustment were: age $(<50$ years, ]50-60], $>60)$ [28], mean duration of consultation $(\leq 20$ min vs $>20)$, mean number of visits weekly ([50-70],]70$100],>100)$ [26], and location of office (Paris vs suburbs) [26]. The absence of strong colinearity between these characteristics was verified by measuring Variance Inflation Factors (maximum: 2.3).

The dependent variables were analyzed first according to the gender of the patient and the GP (with comparison of the inter-GP variances among male and female GPs; our preceding article did not perform this analysis of variance) and then according to the gender of both combined into pairs.

Table 1 Characteristics of male and female patients $(N=2599)$

\begin{tabular}{|c|c|c|c|c|}
\hline & & $\begin{array}{l}\text { Male patients } \\
(N=1259) \\
n(\%)\end{array}$ & $\begin{array}{l}\text { Female patients } \\
(N=1340) \\
n(\%)\end{array}$ & $P$ \\
\hline \multirow[t]{2}{*}{ GP gender } & Male & $782(62.1)$ & $844(63.0)$ & 0.65 \\
\hline & Female & 477 (37.9) & $496(37.0)$ & \\
\hline \multirow[t]{3}{*}{ Age (years) } & {$[40-50[$} & $453(36.0)$ & $499(37.2)$ & 0.28 \\
\hline & {$[50-60[$} & $390(31.0)$ & $425(31.7)$ & \\
\hline & {$[60-75[$} & $416(33.0)$ & $416(31.0)$ & \\
\hline \multirow[t]{3}{*}{ Duration of GP-patient relationship (years) } & {$[0-1]$} & $91(7.3)$ & $77(5.81)$ & 0.007 \\
\hline & ]1-3] & $439(35.2)$ & $407(30.7)$ & \\
\hline & $>3$ & $717(57.5)$ & $841(63.5)$ & \\
\hline \multirow[t]{4}{*}{ Number of consultations annually } & 0 & $186(14.8)$ & $169(12.7)$ & 0.09 \\
\hline & 1 & $170(13.5)$ & $177(13.3)$ & \\
\hline & 2 & 209 (16.6) & $193(14.5)$ & \\
\hline & $>2$ & $691(55.0)$ & $794(59.6)$ & \\
\hline \multirow[t]{3}{*}{$B M l^{\mathrm{a}}\left(\mathrm{kg} / \mathrm{m}^{2}\right)$} & $\leq 25$ & $571(46.6)$ & $846(64.9)$ & $<0.001$ \\
\hline & ]25-30] & $502(41.0)$ & $288(22.1)$ & \\
\hline & $>30$ & $153(12.5)$ & $170(13.0)$ & \\
\hline \multirow[t]{3}{*}{ Educational level } & University year 1-2 & $164(13.3)$ & $190(14.5)$ & 0.46 \\
\hline & Passed 'bac'b & $384(31.1)$ & $424(37.3)$ & \\
\hline & University year 3-4 & $687(55.6)$ & $700(53.3)$ & \\
\hline
\end{tabular}

\footnotetext{
a Body mass index
}

b ' $b_{a c}$ ' is the baccalaureate examination for leaving secondary school
The statistical analyses were performed with SAS software, v. 9.4. The advisory committee for information treatment for health research (commission nationale de l'informatique et des libertés) approved the study, and all patients signed informed consents.

\section{Results}

\section{Description of GPs}

The first 52 GPs who volunteered to participate were included in the study. We review here only the essential aspects of the description of the GPs [19] and their comparison according to gender [2] which have already been presented. Their mean age was 55 years (standard deviation $(S D)=6$ ), and $63 \%$ of them were men. Their mean duration of consultations was $21 \mathrm{~min}(\mathrm{SD}=4.8)$, and on average they saw $92(\mathrm{SD}=23)$ patients weekly. Moreover, the consultations by women GPs lasted longer than those of their male colleagues $(P=0.02)$.

\section{Description of patients}

For the 3640 randomly selected patients, GPs returned 3600 questionnaires (98.8\%), and patients 2605 (71.5\%). Finally, data were collected from both the patient and GP for $71.4 \%(n=2599)$ of the patients included. Patients' mean age was 53.9 years $(\mathrm{SD}=9.5)$ (Table 1$)$. Men had been seeing their GPs for a significantly shorter 
period than the women and had a significantly higher body mass index (BMI).

\section{Gender differences}

Overall, male patients received preventive care significantly more often than women (Table 2). These differences were most marked in the domain of substance use. Moreover, preventive practices were more frequent among women GPs than their male colleagues. These gender differences were nonetheless significant only for smoking status, cardiovascular risk variables, and gynecological cancer screening. The aggregate preventive score was higher for male patients (odds ratio (OR) 1.60, 95\% confidence interval (95\% CI) 1.47-1.75, $P<10^{-4}$ ) and female GPs (OR 1.35, 95\% CI 1.05-1.73, $P=.02$ ).

Except for weight management, the preventive practices explored varied significantly according to the gender composition of the patient-GP pair (Table 3). We thus observed a gradient according to the gender composition of these pairs: the woman patient-male GP pairs systematically had the least frequent preventive practices; the next most frequent was the matching female pairs (patient and GP both women), and then the male pairs. Finally, the male patient-female GP pairs had the most frequent prevention practices.

Regardless of the preventive practice considered, the amplitude of the differences between the patients of each gender was globally similar for male and female GPs. For the aggregate preventive score, the OR for male compared with female patients of male GPs was 1.42 and of female doctors, $1.57(=1.99 / 1.27)$. These results were confirmed by non-significant findings for the tests of interaction between the patients' and GPs' genders (results not shown).

\section{Inter-GP variance}

In the models adjusted for patient characteristics (i.e., taking into account a possible effect of the composition of the patient panels for these characteristics) and GP characteristics, the variance between male GPs was greater than that between women GPs for 7 of the 10 preventive practices analyzed and significantly greater for 4 of them (Table 3). The preventive practices of female GPs were more consistent and homogeneous than those of their male colleagues in terms of lifestyle recommendations and in the cardiovascular risk domain.

\section{Discussion}

Our results show that male patients and female GPs are associated with the most frequent performance of numerous types of preventive care. There was no combined effect of the two protagonists: the effect of the patient's gender is identical among male and female GPs; similarly, the effect of the GP's gender is identical among male and female patients. Accordingly, women patients of male GPs appear to be the patient group least frequently receiving the types of preventive care we studied. Furthermore, it does not appear that the concordance of patient and GP gender influences preventive practices. Finally, women GPs seem to be more consistent in their delivery of preventive practices than their male colleagues.

The results according to patient gender reinforce the findings of studies of the inequality of preventive care that disadvantages women. We must nonetheless point out that our result for the aggregate preventive score disagrees with that of a study conducted among a younger sample of Americans (mean age 45 years); this disparity may be related to interaction between patient age and gender for prevention or to differences in the organization of care between the two countries [29].

Two complementary hypotheses may explain our observations favorable to male patients. The first posits that they may receive more preventive care because epidemiologic evidence indicates that they need it most [30, 31]. According to the second hypothesis, GPs target men for prevention more often because they consider them to be less informed, less aware of risks, and less receptive. It is difficult to determine which of these hypotheses is predominant. The two together probably persuade GPs that the stakes of preventive care are higher for men.

Although women's rates of smoking and drinking [32] are tending to catch up with those of men (the consumption of these two substances increased among women and remained stationary among men, especially for smoking) [33-35], it is in the area of substance use that physicians' preventive practices differ most between genders [36]. This may correspond to their lack of knowledge about recent modifications in these behaviors or to the application of a double standard, that is, a situation in which identical behaviors are judged differently as a function of gender. Excessive alcohol consumption, for example, is much more stigmatizing, even taboo, among women [37]. More or less consciously, such social representations may dissuade physicians from questioning their women patients about their alcohol consumption [38].

Our results about the GP's gender are consistent with the literature [1-4] and underline the positive influence of women physicians in the area of preventive care. While they provide more of this type of care than their male counterparts, only half of these differences are statistically significant. This lack of significance may be due to the relatively small number of GPs, which limits the power of statistical tests (in hierarchical models with random effects, power is linked above all else to the number of GPs analyzed) [39, 40]. For the same reason, the greater homogeneity of preventive practices among 


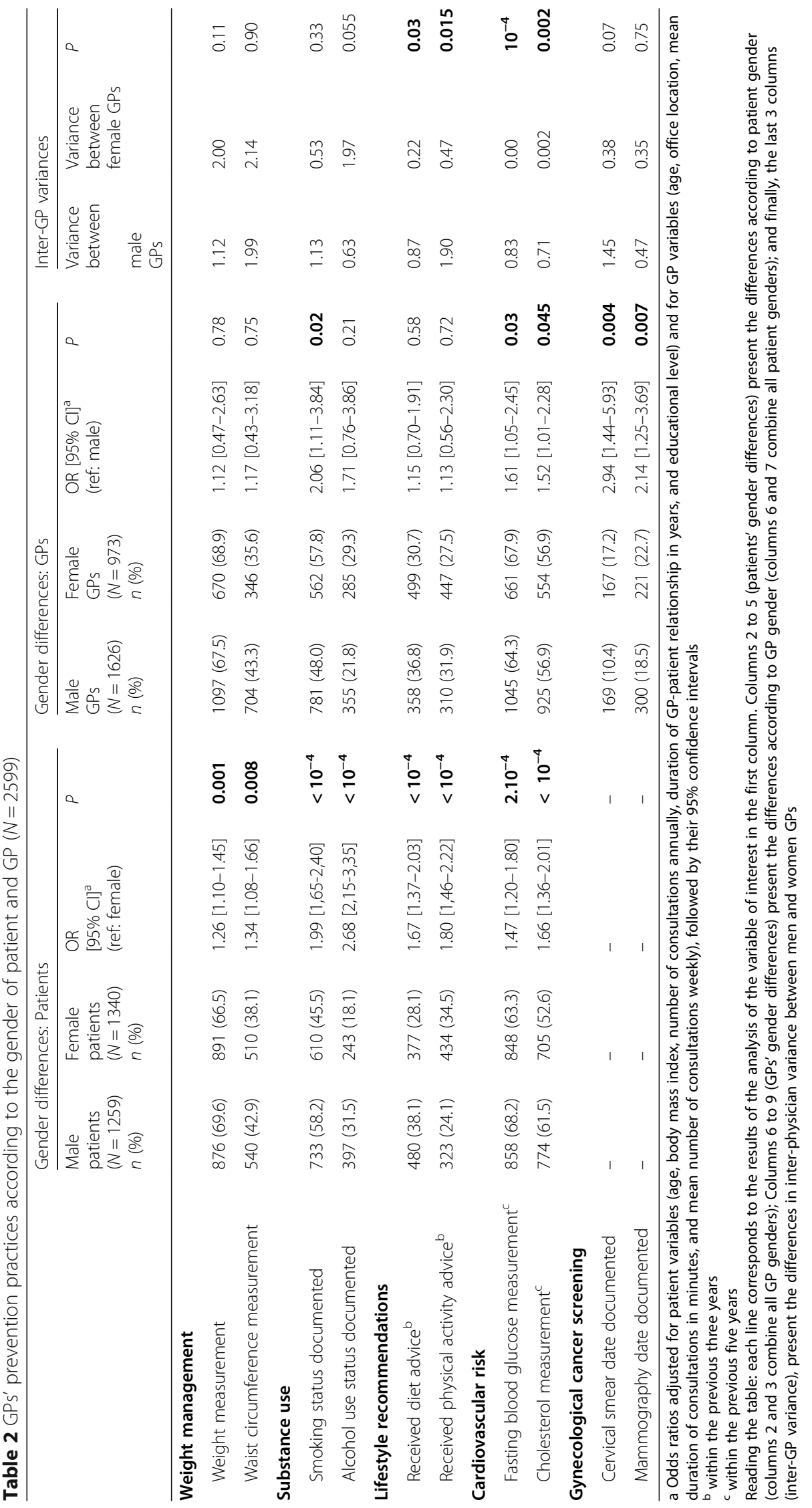


Table 3 GPs' prevention practices and aggregate preventive score according to the gender composition of the patient-GP pair $(N=2599)$

\begin{tabular}{|c|c|c|c|c|}
\hline & Gender composition of the patient-GP pair ${ }^{d}$ & $\%$ & $\mathrm{OR}[95 \% \mathrm{Cl}]^{\mathrm{a}}$ & $P$ \\
\hline \multirow[t]{4}{*}{ Weight measurement } & $\mathrm{F} / \mathrm{M}$ & 66.0 & 1 & 0.11 \\
\hline & $F / F$ & 67.3 & $1.76[0.60-5.20]$ & \\
\hline & $\mathrm{M} / \mathrm{M}$ & 69.1 & $1.25[0.95-1.66]$ & \\
\hline & $M / F$ & 70.4 & $1.76[0.60-5.21]$ & \\
\hline \multirow[t]{4}{*}{ Waist circumference measurement } & $\mathrm{F} / \mathrm{M}$ & 33.3 & 1 & 0.045 \\
\hline & $F / F$ & 32.3 & $1.07[0.40-2.92]$ & \\
\hline & $\mathrm{M} / \mathrm{M}$ & 45.3 & $1.25[0.95-1.64]$ & \\
\hline & $M / F$ & 39.0 & $1.60[0.60-4.34]$ & \\
\hline \multirow[t]{4}{*}{ Smoking status documented } & $\mathrm{F} / \mathrm{M}$ & 41.8 & 1 & $<10^{-4}$ \\
\hline & $\mathrm{F} / \mathrm{F}$ & 51.8 & $2.18[1.16-4.08]$ & \\
\hline & $\mathrm{M} / \mathrm{M}$ & 54.7 & $2.07[1.64-2.62]$ & \\
\hline & $M / F$ & 63.9 & $4.04[2.14-7.63]$ & \\
\hline \multirow[t]{4}{*}{ Alcohol use status documented } & F/M & 15.6 & 1 & $<10^{-4}$ \\
\hline & $F / F$ & 17.3 & $1.76[0.76-4.05]$ & \\
\hline & $\mathrm{M} / \mathrm{M}$ & 28.5 & $2.73[2.05-3.64]$ & \\
\hline & $M / F$ & 36.5 & $4.59[2.01-10.47]$ & \\
\hline \multirow[t]{4}{*}{ Received diet advice $^{b}$} & $\mathrm{~F} / \mathrm{M}$ & 26.3 & 1 & $<10^{-4}$ \\
\hline & $F / F$ & 31.3 & $1.03[0.61-1.76]$ & \\
\hline & $\mathrm{M} / \mathrm{M}$ & 35.4 & $1.54[1.19-1.98]$ & \\
\hline & $M / F$ & 42.6 & $1.95[1.15-3.31]$ & \\
\hline \multirow[t]{4}{*}{ Received physical activity advice ${ }^{b}$} & $\mathrm{~F} / \mathrm{M}$ & 22.3 & 1 & $<10^{-4}$ \\
\hline & $\mathrm{F} / \mathrm{F}$ & 27.2 & $1.82[0.57-2.44]$ & \\
\hline & $\mathrm{M} / \mathrm{M}$ & 33.1 & $1.86[1.42-2.44]$ & \\
\hline & $M / F$ & 36.7 & $2.04[0.99-4.18]$ & \\
\hline \multirow[t]{4}{*}{ Fasting blood glucose measurement ${ }^{c}$} & $\mathrm{~F} / \mathrm{M}$ & 61.7 & 1 & $2.10^{-4}$ \\
\hline & $\mathrm{F} / \mathrm{F}$ & 65.9 & $1.51[0.96-2.36]$ & \\
\hline & $\mathrm{M} / \mathrm{M}$ & 67.0 & $1.40[1.08-1.80]$ & \\
\hline & $M / F$ & 70.0 & $2.41[1.52-3.84]$ & \\
\hline \multirow[t]{4}{*}{ Cholesterol measurement $^{c}$} & $\mathrm{~F} / \mathrm{M}$ & 53.4 & 1 & $10^{-4}$ \\
\hline & $F / F$ & 51.2 & $1.24[0.80-1.91]$ & \\
\hline & $\mathrm{M} / \mathrm{M}$ & 60.6 & $1.40[1.09-1.78]$ & \\
\hline & $M / F$ & 62.9 & $2.69[1.72-4.20]$ & \\
\hline \multirow[t]{4}{*}{ Preventive aggregate score } & $\mathrm{F} / \mathrm{M}$ & 41.1 & 1 & $<10^{-4}$ \\
\hline & $F / F$ & 43.7 & 1.27 [0.95-1.69] & \\
\hline & $\mathrm{M} / \mathrm{M}$ & 49.2 & $1.42[1.31-1.53]$ & \\
\hline & $M / F$ & 52.8 & $1.99[1.48-2.66]$ & \\
\hline
\end{tabular}

${ }^{a}$ Odds ratios adjusted for patient variables (age, body mass index, number of consultations annually, duration of GP-patient relationship, and educational level) and for GP variables (age, office location, mean duration of consultations, and mean number of consultations weekly), followed by their $95 \%$ confidence intervals ${ }^{b}$ within the previous three years

c within the previous five years

${ }^{d}$ numbers in pair sets: $F / M=496 ; F / F=782 ; M / M=477 ; M / F=844$

women GPs, measured by the variance between them, should perhaps be analyzed in a larger GP sample.

Several sociological explanations help to interpret our findings related to GP gender. Educational practices in school promote originality more in boys and obedience in girls $[41,42]$ and may thus contribute to the propensity of male GPs to distance themselves from guidelines and that of women to comply with them. The traditional 
social roles of women also tend to construct a relation to time more oriented toward the planning of tasks and marked by a concern about consequences, which tends to be an asset in the area of prevention. Finally, although women today comprise a substantial portion of the medical world, their entry into this professional universe dominated by men is nonetheless recent [43]. In a quest for legitimacy, they may have had to demonstrate their willingness to conform to professional rules and especially guidelines [44]. Next, specifically for gynecological cancer screening, it is possible that the lack of investment by male GPs may be in part due to their female patients' preference to have these tests performed by women $[45,46]$. Finally, another part of these genderbased differences in preventive practices may be due to women's more thorough recording of their practices. Women's dispositions related to writing (effective notetaking acquired during their student life [44], writing lists and managing family organization in the domestic sphere) and differences in their organization of their professional practice (shorter working hours leading to greater file-sharing) [47] may combine to makes preventive management by women more traceable.

Our simultaneous analysis of patient and GP gender does not show that their concordance influenced care. Our observations thus do not support the hypothesis that a mirror-effect between patient and GP favors quality care. Moreover, although women GPs appear to provide more preventive care, they do so in a manner as inegalitarian, that is, favoring male patients, as their male colleagues. These differences raise issues beyond their ethical aspects, for recent work has demonstrated that some risk factors have a stronger, more negative effect on women than men. This is the case, for example, for diabetes as a cardiovascular risk factor [48] and for smoking and lung cancer [49].

Our study has also some strengths: its setting in general practice, different from the preceding studies, which have taken place essentially in hospitals or with specialists; consideration of the hierarchical structure and the non-independence of patients with mixed models; and the numerous adjustments for patient and GP characteristics known to be associated with prevention, which limit the possibility of residual confounding.

Our study also has several limitations. First, our analyses are not adjusted for patients' individual history of diabetes and cardiovascular disease, although these are factors that underlie physicians' preventive practices. We conducted sensitivity analyses by adjusting for this history and determined that it did not modify our results. Next, it did not take into account the health behaviors of the GPs, which are nonetheless likely to modify their preventive practices. Male GPs smoked more than their female colleagues $[50,51]$ and the current or previous smoking status of doctors affects their investment in smoking cessation [51]. Accordingly, not considering this type of characteristic is likely to lead to overestimating the differences between male and female GPs.

In France, prevention is one of the missions explicitly assigned to GPs. There is no type of facility or practice specifically devoted to prevention, and the use of practice nurses in GPs' offices is just barely beginning in this country. Although access to specialists is relatively easy, only gynecologists will contribute to the gynecological cancer screening of a significant proportion of the population. Although these specificities related to health care in France may present problems about the generalization of our results to other countries, the fact that French GPs are relatively alone in ensuring preventive care enables the study of the influence of their gender about the preventive care dispensed. Moreover, the epidemiologic data about healthy behaviors globally less adopted by men and the male domination of the medical world, that is, the low concentration of women physicians within some specializations $[52,53]$ and their limited access to leadership positions in academic medicine $[54,55]$ are widely shared in much of the West. Consequently, although the male-female gaps observed may vary from one country to another, our results are probably at least qualitatively generalizable.

In this work, we adopted an analysis founded on equality (each managed the same) because the guidelines do not indicate any reason for different management according to the patients' gender. Equity (to each according to his/her need) might also be an interesting point of view for this analysis, insofar as the needs for prevention are not necessarily the same for men and women. This may lead us to subsequent work on this topic.

\section{Conclusion}

In conclusion, physicians, especially those providing primary care, must be made aware of these differences in their preventive practices, in relation to both their patients' gender and their own. They must realize that the way they approach prevention, health behaviors, and patients' risky practices is rarely neutral in relation to gender and that it directly affects their medical activities. Although the increasing feminization of medicine should result in the increased use of preventive care, the differences in practices prejudicial to women may well continue, independently of demographic changes. To improve this situation, the influence of sex and gender (in their biological and social dimensions) on health and illness and its implications for practice should be covered more thoroughly in the medical school curriculum.

Abbreviations

BMI: Body mass index; GP: General practitioner 


\section{Acknowledgements}

Not applicable

\section{Authors' contributions}

L.R, H.F and V.R designed the work; R.D, R.L and H.P performed the statistical analysis of the data; R.D, L.R, V.R and G.B wrote the manuscript. All authors read and approved the final manuscript.

\section{Funding}

The sources of funding for this work was the Groupement régional de santé publique d'lle de France, the Conseil regional d'lle de France, the National Institute for Prevention and Health Education (INPES, Institut national de prévention et d'éducation pour la santé) and the "la personne en médecine" program of Sorbonne Paris Cité University. The funders had no role in study design, data collection and analysis, decision to publish, or preparation of the manuscript."

\section{Availability of data and materials}

The datasets used and/or analysed during the current study are available from the corresponding author on reasonable request. The English questionnaires are available upon request.

\section{Ethics approval and consent to participate}

The advisory committee for information treatment for health research (commission nationale de l'informatique et des libertés) approved the study, and all patients signed informed consents.

\section{Consent for publication}

Not applicable

\section{Competing interests}

The authors declare that they have no competing interests.

\section{Author details}

'General Practice Department, Université Paris-Saclay, Le Kremlin Bicêtre, France. ${ }^{2}$ LEDi, EA 7467, University of Burgundy Franche-Comté, Dijon, France. ${ }^{3}$ CESP, INSERM, Paris-Saclay University, Paris-Sud University, UVSQ, Villejuif, France. ${ }^{4}$ Institut National d'Études Démographiques (INED), Paris, France.

${ }^{5}$ Société de Formation Thérapeutique du Généraliste, Paris, France.

\section{Received: 18 February 2019 Accepted: 20 March 2020}

\section{Published online: 20 April 2020}

\section{References}

1. Tabenkin H, Eaton CB, Roberts MB, Parker DR, McMurray JH, Borkan J. Differences in Cardiovascular Disease Risk Factor Management in Primary Care by Sex of Physician and Patient. Ann Fam Med. 2010;8(1):25-32.

2. Delpech R, Ringa V, Falcoff H, Rigal L. Primary prevention of cardiovascular disease: more patient gender-based differences in risk evaluation among male general practitioners. Eur J Prev Cardiol. 2016;23(17):1831-8.

3. Turnbull F, Arima H, Heeley E, Cass A, Chalmers J, Morgan C, et al. Gender disparities in the assessment and management of cardiovascular risk in primary care: the AusHEART study. Eur I Cardiovasc Prev Rehabil Off J Eur Soc Cardiol Work Groups Epidemiol Prev Card Rehabil Exerc Physiol. 2011; 18(3):498-503.

4. Krähenmann-Müller S, Virgini VS, Blum MR, da Costa BR, Collet T-H, Martin Y, et al. Patient and physician gender concordance in preventive care in university primary care settings. Prev Med. 2014;67:242-7.

5. Holund U, Thomassen A, Boysen G, Charles P, Eriksen EF, Overvad K, et al. Importance of diet and sex in prevention of coronary artery disease, cancer, osteoporosis, and overweight or underweight: a study of attitudes and practices of Danish primary care physicians. Am J Clin Nutr. 1997;65(6 Suppl):2004S-6S.

6. Hebl MR, Xu J. Weighing the care: physicians' reactions to the size of a patient. Int J Obes Relat Metab Disord J Int Assoc Study Obes. 2001;25(8): $1246-52$.

7. Lofters AK, Ng R, Lobb R. Primary care physician characteristics associated with cancer screening: a retrospective cohort study in Ontario, Canada. Cancer Med. 2015;4(2):212-23.
8. Ince-Cushman D, Correa JA, Shuldiner J, Segouin J. Association of primary care physician sex with cervical cancer and mammography screening. Can Fam Physician Med Fam Can. 2013;59(1):e11-8.

9. Collange F, Fressard L, Pulcini C, Sebbah R, Peretti-Watel P, Verger P. General practitioners' attitudes and behaviors toward HPV vaccination: A French national survey. Vaccine. 2016;34(6):762-8.

10. Lurie N, Slater J, McGovern P, Ekstrum J, Quam L, Margolis K. Preventive care for women. Does the sex of the physician matter? N Engl J Med. 1993; 329(7):478-82.

11. Schmittdiel JA, Traylor A, Uratsu CS, Mangione CM, Ferrara A, Subramanian U. The Association of Patient-Physician Gender Concordance with cardiovascular disease risk factor control and treatment in diabetes. J Womens Health. 2009;18(12):2065-70.

12. Pickett-Blakely O, Bleich SN, Cooper LA. Patient-physician gender concordance and weight-related counseling of obese patients. Am J Prev Med. 2011;40(6):616-9.

13. Schieber A-C, Delpierre C, Lepage B, Afrite A, Pascal J, Cases C, et al. Do gender differences affect the doctor-patient interaction during consultations in general practice? Results from the INTERMEDE study. Fam Pract. 2014; 31(6):706-13.

14. Kim C, McEwen LN, Gerzoff RB, Marrero DG, Mangione CM, Selby JV, et al. Is physician gender associated with the quality of diabetes care? Diabetes Care. 2005;28(7):1594-8.

15. Baumhäkel M, Müller U, Böhm M. Influence of gender of physicians and patients on guideline-recommended treatment of chronic heart failure in a cross-sectional study. Eur J Heart Fail. 2009;1 1(3):299-303.

16. Primon J, Frickey A. Les manieres sexuees d'etudier en premiere annee d'universite, Gender Differences in Higher Education : How Male and Female Students. Sociétés Contemp. 2002;48(4):63-85.

17. Malmartel A, Rigal L. Gynaecologic follow up, physicians involved and cervical smears: An accumulation of social disparities. J Gynecol Obstet Biol Reprod (Paris). 2016;45(5):459-66.

18. Thebault J-L, Falcoff H, Favre M, Noël F, Rigal L. Patient-physician agreement on tobacco and alcohol consumption: a multilevel analysis of GPs' characteristics. BMC Health Serv Res. 2015;15:110.

19. Thebault J-L, Ringa V, Bloy G, Pendola-Luchel I, Paquet S, Panjo H, et al. Are primary-care physician practices related to health behaviors likely to reduce social inequalities in health? Prev Med juin. 2017:99:21-8.

20. Casanova L, Ringa V, Bloy G, Falcoff H, Rigal L. Factors associated with GPs' knowledge of their patients' socio-economic circumstances: a multilevel analysis. Fam Pract. 2015;32(6):652-8.

21. Asch SM, Kerr EA, Keesey J, Adams JL, Setodji CM, Malik S, et al. Who is at greatest risk for receiving poor-quality health care? N Engl J Med. 2006; 354(11):1147-56.

22. McGlynn EA, Asch SM, Adams J, Keesey J, Hicks J, DeCristofaro A, et al. The quality of health care delivered to adults in the United States. N Engl J Med. 2003:348(26):2635-45.

23. Potter MB, Vu JD, Croughan-Minihane M. Weight management: what patients want from their primary care physicians. J Fam Pract. 2001;50(6):513-8.

24. Sciamanna CN, Tate DF, Lang W, Wing RR. Who reports receiving advice to lose weight? Results from a multistate survey. Arch Intern Med. 2000; 160(15):2334-9.

25. Peretti-Watel P. La prévention primaire contribue-t-elle à accroître les inégalités sociales de santé ? Rev DÉpidémiologie Santé Publique. 2013; 61(Supplement 3):S158-62.

26. Pelletier-Fleury N, Le Vaillant M, Hebbrecht G, Boisnault P. Determinants of preventive services in general practice. Health Policy. 2007;81(2-3):218-27.

27. Cornelius LJ, Smith PL, Simpson GM. What factors hinder women of color from obtaining preventive health care? Am J Public Health. 2002; 92(4):535-9.

28. Christian AH, Mills T, Simpson SL, Mosca L. Quality of cardiovascular disease preventive care and physician/practice characteristics. J Gen Intern Med. 2006;21(3):231-7.

29. Dutton GR, Herman KG, Tan F, Goble M, Dancer-Brown M, Van Vessem $\mathrm{N}$, et al. Patient and physician characteristics associated with the provision of weight loss counseling in primary care. Obes Res Clin Pract. 2014;8(2):e115-200.

30. Martin A-C MJ. Maladie coronaire de la femme. EMC - Cardiol. 2008;3(1):1-7.

31. Lee PY, Alexander KP, Hammill BG, Pasquali SK, Peterson ED. Representation of elderly persons and women in published randomized trials of acute coronary syndromes. JAMA. 2001;286(6):708-13. 
32. Taschini E, Urdapilleta I, Verlhiac J-F, Tavani JL. Représentations sociales de l'alcoolisme féminin et masculin en fonction des pratiques de consommation d'alcool, Social representations of female and male alcoholism : The influence of alcohol consumption. Cah Int Psychol Soc. 2015;107(3):435-61.

33. Guignard R, Beck F, Richard J-B. La consommation de tabac en France en 2014 : caractéristiques et évolutions récentes. Evolution. 2015;31:4.

34. Beck F, Guignard R, Richard JB, Tovar ML, Spilka S. Les niveaux d'usage des drogues en France en 2010 - Exploitation des données du Baromètre santé - Tendances 76 - 2011 - OFDT.

35. Pasquereau A, Andler R, Guignard R, Richard J-B, Arwidson P, Nguyen-Thanh $\checkmark$. La consommation de tabac en France : premiers résultats du baromètre santé 2017. Bulletin Epidémiologique Hebdomadaire, 2018, n. 14-15, p. 265273.

36. Nolen-Hoeksema S. Gender differences in risk factors and consequences for alcohol use and problems. Clin Psychol Rev. 2004;24(8):981-1010.

37. Sledziewski EG. The image of smoking women in France. J Gynecol Obstet Biol Reprod (Paris). 2005;34(1):3S270-4.

38. Karoll BR. Women and Alcohol-Use Disorders: A Review of Important Knowledge and Its Implications for Social Work Practitioners. J Soc Work. 2002;2(3):337-56.

39. Rietbergen C, Moerbeek M. The Design of Cluster Randomized Crossover Trials. J Educ Behav Stat. 2011;36(4):472-90.

40. Kreft IGG, de Leeuw J. Introducing multilevel modeling. London. Thousand Oaks: Sage; 1998.

41. Mosconi N. L'égalité des sexes en éducation et formation. In: Presses universitaires de France; 1998.

42. Duru-Bellat M. L'école des filles: quelle formation pour quels rôles sociaux ? In: L'harmattan; 2004. p. 33.

43. Pringle R. Sex and medicine: gender, power and Authority in the Medical Profession. 1 edition. Cambridge. New York: Cambridge University Press; 1998. p. 252.

44. Duru-Bellat M. L'école des filles : Quelle formation pour quels rôles sociaux? I'harmattan; 2002.

45. Olaza-Maguiña AF, De la Cruz-Ramirez YM. Barriers to the non-acceptance of cervical cancer screenings (pap smear test) in women of childbearing age in a rural area of Peru. Ecancermedicalscience. 2019;13:901.

46. Maza M, Melendez M, Masch R, Alfaro K, Chacon A, Gonzalez E, et al. Acceptability of self-sampling and human papillomavirus testing among non-attenders of cervical cancer screening programs in El Salvador. Prev Med. 2018;114:149-55.

47. Lapeyre N, Feuvre NL. Féminisation du corps médical et dynamiques professionnelles dans le champ de la santé, Abstract. Rev Fr Aff Soc. 2005: (1):59-81.

48. Garcia M, Mulvagh SL, Merz CNB, Buring JE, Manson JE. Cardiovascular Disease in Women. Circ Res. 2016;118(8):1273-93.

49. Yusuf S, Hawken S, Ounpuu S, Dans T, Avezum A, Lanas F, et al. Effect of potentially modifiable risk factors associated with myocardial infarction in 52 countries (the INTERHEART study): case-control study. Lancet Lond Engl. 2004;364(9438):937-52

50. Josseran L, King G, Velter A, Dressen C, Grizeau D. Smoking behavior and opinions of French general practitioners. J Natl Med Assoc. 2000; 92(8):382-90.

51. Josseran L, King G, Guilbert P, Davis J, Brücker G. Smoking by French general practitioners: behaviour, attitudes and practice. Eur J Public Health. 2005;15(1):33-8.

52. Riska E. Towards gender balance: but will women physicians have an impact on medicine? Soc Sci Med 1982. 2001;52(2):179-87.

53. Boulis AK, Jacob JA. The Changing Face of Medicine: Women Doctors and the Evolution of Health Care in America, vol. 435; 2011.

54. Carnes M, Morrissey C, Geller SE. Women's health and Women's leadership in academic medicine: hitting the same glass ceiling? J Womens Health. 2008;17(9):1453-62.

55. Kilminster S, Downes J, Gough B, Murdoch-Eaton D, Roberts T. Women in medicine--is there a problem? A literature review of the changing gender composition, structures and occupational cultures in medicine. Med Educ. 2007:41(1):39-49.

\section{Publisher's Note}

Springer Nature remains neutral with regard to jurisdictional claims in published maps and institutional affiliations.

Ready to submit your research? Choose BMC and benefit from:

- fast, convenient online submission

- thorough peer review by experienced researchers in your field

- rapid publication on acceptance

- support for research data, including large and complex data types

- gold Open Access which fosters wider collaboration and increased citations

- maximum visibility for your research: over $100 \mathrm{M}$ website views per year

At BMC, research is always in progress.

Learn more biomedcentral.com/submissions 